\title{
Impact of Oil Prices on Stock Market Performance: Evidence from Top Oil Importing Countries
}

\author{
Muhammad Ali * $\quad$ Khalid M. Iraqi ${ }^{\dagger} \quad$ Abdul Waheed Khan ${ }^{\ddagger}$
}

\begin{abstract}
This study aims to analyze the impact of oil price on stock market performance in top oil importing countries. We used balanced panel data over a sample period of 1995 to 2017 with annual frequency. The sample data was gathered from World Development Indicator (WDI), Global Financial Indicator (GFDI) and West Texas Intermediate (WTI). The sample data were analyzed using regression test under the assumptions of Hausman test. Findings obtained from the fixed effect model suggest that oil price has a negative and insignificant impact on stock market. Similarly, the exchange rate also showed negative and insignificant impact while inflation showed negative but significant impact on stock market. Moreover, GDP showed a positive and significant influence on stock market. Overall, this study recommends that the policy makers should anticipate the changes in oil prices in order to improve the health of stock market.
\end{abstract}

Keywords: Oil price, stock market, exchange rate, economic growth, inflation, oil importing countries.

\section{Introduction}

The oil prices are subjected to rapid escalation and downfall over the past recent years. To this end, the modifications in oil prices influence the economic activity of both emerging and developed countries (Alrub, Rjoub, Aga, Bein, et al., 2018; Alzyoud, Wang, \& Basso, 2018; Arfaoui \& Ben Rejeb, 2017). One of the core attributes of oil exporting countries is their sensitivity and stability toward oil price fluctuations, which is rooted from their major reliance on oil as well as on the paucity of diversification in their specific economic development (Degiannakis, Filis, \& Panagiotakopoulou, 2018; Ewing, Kang, \& Ratti, 2018; Fowowe, 2017). Similarly, the effect of oil price fluctuations on the inflation anticipation, monetary policy, investor confidence, and production cost has been investigated several times. For instance, in the context of United States (US), one study has examined the fluctuations in the oil price that shows a negative impact on the development of its economy (Mollick \& Nguyen, 2015). In support to this claim, several studies have affirmed that there presents a substantial non-linear association between the macro-economy variables and oil price (Ji, Liu, Zhao, \& Fan, 2018; Maghyereh \& Al-Kandari, 2007).

Additionally, the barometer of the national economy is considered to be the stock market in terms of inflation, cash flow, and the interest rate. Moreover, there is a significant

\footnotetext{
*IQRA University Karachi, Pakistan. Email: dr.mali@iqra.edu.pk

${ }^{\dagger}$ Department of Public Administration, University of Karachi, Karachi, Pakistan. E-mail: vc@uok.edu.pk

${ }^{\ddagger}$ IQRA University, Karachi, Pakistan.
} 
impact on interest rate, growth, and inflation as the crude oil is vitally significant in majorly economic development actions in oil import countries (Wong \& El Massah, 2018; Yao, Kuang, \& Lin, 2018; Zhu, Guo, You, \& Xu, 2016). The variations in oil prices will potentially influence on the behavior of stock prices in accordance with the pricing model of stock cash flow. In addition, increasing oil prices will augment construction prices, which result in a lesser extent of success and lead to a downfall in the future anticipated cash flow of the company with a succeeding reduction of the share price (Nusair \& Olson, 2019; Sharma et al., 2018). Over the last ten years, oil price fluctuations have been prominent. Prices between 2007 and 2009 increased from $60 t o 145$ after an extremely calm twenty-year period between 1986 and 2006. However, there was an emerging reduction found to $\$ 30$ in the period from 2007 and 2009 (Nusair \& Al-Khasawneh, 2017). From the periods of 2014-2017, there was also a sluggish downfall to $75 \%$ of oil prices throughout a few months.

Shocks in oil prices put impact over stock market by means of fluctuation. These impacts occur on the basis of unpredicted vulnerabilities in oil prices that fluctuates the cash flows of a particular firm, which in return moves in the direction of uncertainties of stock market (Wong \& El Massah, 2018). It is the fact that listed companies face challenges, by means of high volatility in stocks, due to the variations in oil price (Fowowe, 2017). However, extensive researches have been conducted about the price effect of crude oil upon stock market, but still no final conclusion has been drawn. Earlier studies further illustrate that stock market faces negative outcomes due to the variation in oil prices (Naser \& Rashio, 2018). On the contrary, it is illustrated that changes in oil price positively predict the stocks; while evidence found that country's economic arrangements heavily intervene between the connection of oil shocks and stock price (Ji et al., 2018). Moreover, evidence of various studies exhibits that stock price has not impacted by the fluctuation in oil price. Though, numerous researches prove that the dynamics of oil price impact upon various activities of an economy (Alzyoud et al., 2018; Nusair \& Olson, 2019; You, Guo, Zhu, \& Tang, 2017). Furthermore, oil price increment tends to incur or evolve the effect of inflation (Kang, Ratti, \& Vespignani, 2017). In the same way, stock performance notably predicted through oil price that ultimately influences upon economy from a broader perspective (Marashdeh \& Afandi, 2017; Sharma et al., 2018).

Somehow, the important aspect has been neglected in these studies that the inclusion of exchange rate might show notable outcomes derive from the influence of oil price on stocks (Aloui, Hammoudeh, \& Nguyen, 2013; Nusair \& Olson, 2019). In addition, it is possible that oil shocks predict stocks differently if stock market possesses bearish characteristics rather than bullish, and it might shows asymmetric to symmetric shocks of oil price rather than negative fluctuation (Liao, Shi, \& Xu, 2018). Henceforth, the phenomenon between oil price and stocks are different and it depends upon the nature of shocks and market atmosphere (Ready, 2017; Yao et al., 2018). Recent studies also investigated the link between oil prices fluctuations and macroeconomic variables (Alrub et al., 2018; Fowowe, 2017). 


\section{Literature Review}

The increase of oil will expand consumption as well as an investment using the income and wealth channels and consequently economic activity and actual GDP for oil-related companies. In addition, relying on elasticities of oil demand are levied when oil royalties might increase if oil prices rise for governments in oil-importing countries (Ready, 2017). These royalties might be utilized for further domestic government spending in order to expand transfer payments to households or to establish the domestic infrastructure and; therefore, drive to additional economic stimulus (Zhang \& Jiang, 2017). In addition, it has been believed that the interest rate used to discount the anticipated future cash flows has relied on the effects of oil price shocks in the stock-pricing formula. Anticipated inflation and real rates of interest have entirely relied on the nominal interest rates. These prices relied on supply connections and aggregate demand connections in an economy, which are affected by fiscal and monetary policies as well as trade effects comprehensively (Basher, Haug, \& Sadorsky, 2017).

In oil-importing countries, an economic downturn will influence non-oil related exportsinitiated oil-importing countries. Oil importing countries will observe a negative stimulus seeking through the trade channel when relying on the size of the non-oil import sector in oil- importing countries (Al-hajj, Al-Mulali, \& Solarin, 2017). There will be positive or negative effects of the net effect for oil importing countries. For instance, being a net oil importer, Norway has taken advantages from the increase in oil prices, which shows a temporary rise in economic growth. Contrarily, being a net oil exporter, the economic growth of Canada has been declined comparatively to the effects of oil price rises in oilimporting countries (Le \& Chang, 2012).

The outcomes of declining oil prices seek the concentration of various economists, as they sought to illustrate nature of the relationship between oil price fluctuations and behavior of government expenditure (Adetunji Babatunde, Adenikinju, \& Adenikinju, 2013). According to Keynesian theories, the mitigation of consumption, investment and total demand occur due to the decrease of public expenditure, which consequently influences upon the economic growth negatively (Algahtani, 2016). In theory, investment, economic growth and public spending likewise fluctuate due to the change in oil price. However, in oil-exporting nations the effect of oil price fluctuations, is not the same as oil-importing nation, upon economic growth and government expenditure. Economically, the main machine, which runs the economy, is an industrial sector. Similarly, it contributes heavily to the GDP of a particular nation as compared to various businesses. Historically, GDP majorly affected by shocks in oil prices. The percentage of oil revenue contribution to GDP in 2014 is $71.1 \%$ and $87.5 \%$ of total exports and total revenues, respectively (Degiannakis et al., 2018).

The Saudi oil sector contributed over $40 \%$ to the Kingdom's overall GDP (Aloui et al., 2013). Moreover, movement in the non-oil sector is connected with oil prices by means of government spending during fluctuation periods. Since Saudi Arabia is a large oilexporting country, its public spending policy is directly linked to oil prices and its revenue accounts for a substantial part of the public budget (Aloui et al., 2013). As a result, when oil prices change, the government accordingly adjusts its policy toward its expen- 
diture. The role of the government's fiscal policy is determined by the fluctuations in oil prices, which is transmitted to the entire national economy (Mohanty, Onochie, \& Alshehri, 2018).

Arfaoui and Ben Rejeb (2017) focused on the US economy and addressed one of the most imperative works on the effect of oil price over economy. The study contended that there is a presence of indirect link of oil price with the economic events. The findings became broadly recognized at the macroeconomic level. The fluctuations in oil price explained its importance in approximately every recession in the US over the period of 1949 till 1973 era. The study concluded about the fluctuation in GNP and Unemployment due to the oil price vulnerabilities, in the context of US (Ghorbel, Abbes Boujelbene, \& Boujelbene, 2014; Zhu et al., 2016).

Ready (2017) stated that fluctuations in oil price boost the activities to reallocate the resources in non-productive way from a productive manner that puts a heavy burden on the economy. Mollick and Nguyen (2015) contended that oil price fluctuations of the early 1970s have different effects on different economies. However, Nusair and Olson (2019) determined a significant link of oil price fluctuations with macroeconomic indicators. By using data for the period 1948-1972, Zhu et al. (2016) confirmed Hamilton's results that oil price fluctuations are directly related to and influence GDP growth. The findings of Hamilton proved about the strong causal and negative correlation of oil price fluctuation with real GNP growth of U.S. Ji et al. (2018) investigated how oil price fluctuations affect macro-economy behavior in an oil-importing nations through implementing DSGE model in Mexico and Norway, along with diverse fiscal policy framework. The research revealed that crucial rule has been played by fiscal policy to convey oil price fluctuations in an economy by affecting instability outcomes and growth. Therefore, when the prices of oil fall, the government cuts its expenditure (Hamdi \& Sbia, 2013). Ewing et al. (2018) found an inverse influence of energy and oil vulnerabilities over actual activities of US economy.

Moreover, oil market has been described with an unpredictable drive of oil price fluctuations since the 1970s. Aloui et al. (2013) proposed about the oil price fluctuation is not a new phenomenon. It has been a foremost feature in the oil market during the last three decades. There have been very large and sharp oil price fluctuations since its first collapse in 1986. Alrub et al. (2018) evaluated oil price fluctuations phenomenon on the real economic behavior by using seven countries of OECD. The overall decline in oil prices has less control upon GDP than the escalated oil prices. Oil prices escalation showed mixed force (positive and negative) on economic activity; while, the connections of oil-importing economies are negative. Marashdeh and Afandi (2017) inspected the association of oil price variations with economic growth of Singapore by using VEC Model based on cointegration. Hence, findings suggested that oil price fluctuations had a negligible result on the performance of the macroeconomic growth of Singapore.

Government Expenditure and oil prices fluctuation possess positive association. This association is significant and linked to the rise of increasing oil revenues by the government to improve other economic sectors, such as agriculture, education, and infrastructure. These sectors are the components of various government capital and expenditures. Naser and Rashio (2018) explained about the exports of natural resources that tend to unstable the expenditure of the government. Maghyereh and Al-Kandari (2007) tested the 
causality trend among government spending and revenue by using an error-correction and co-integration modeling framework for the period of 1980-2000, in the context of GCC nations. Their results indicated that escalation of revenue leads towards the escalated spending of the government at the first level. Basher et al. (2017) tried to predict the activities of the economy by analyzing shocks of oil price, in the Nigerian settings through applying the VAR model. The findings exhibit that any escalation of oil prices directly moves in the direction of increased spending of the government, inflation, and industrial production growth.

Le and Chang (2012) found that most of the large flows in public capital spending during positive fluctuations times are non-productive and have a very low return. Kang et al. (2017) stated that negative oil price fluctuations may cause a decrease in economic growth as compared to the positive ones. A negative fluctuation fosters adjustment in government expenditures, which might be very costly. Dependability on cutting current expenditures is unsatisfactory because of its negative social consequences.

$\mathrm{Hu}$, Liu, Pan, Chen, and Xia (2018) studied the structure of shock in oil prices along with the irregular impacts of oil price shock on the stock market of China. The samples studied in this study include the output of global gross crude oil, the global index of economy, the crude oil real prices, Shenzhen component index and Shanghai Composite Index. Monthly data was taken for the time period from August 2004 to August 2016. To identify the average demand shock supply shock and the shock of oil specific market, this study used the model of SVAR. Then the model of NARDL was used to study the long and short-run effects of shocks related to oil prices on the composite index of Shanghai and the Component Index of Shenzhen in the Chinese stock. The results highlighted that the specific demand shock of oil market and the average demand shock have a major impact on the oil price movements while this movement of oil price is very little affected by the supply shock. Secondly, the study has revealed the findings about the structural oil shocks effects on the Chinese stock market price index that, there is no substantial influence of aggregate demand shock and supply shock on the stock index of China in long run. However, it was found that the positive and disruptive shocks in the specific demand of oil market have a significant impact on the Composite Index of Shanghai and the Component Index of Shenzhen.

Alzyoud et al. (2018) studied the developments of the Canadian exchange rate, COPs and the stock index. They studied the long run association between these factors and the long run elasticity between these variables. For this purpose, they collected the monthly data of the COP, the exchange rate between CAD/USD and the Canadian stock market for a period from 1986 to 2015. Statistics Canada's CANSIM was used for the collection of nominal exchange rate data (Canadian dollar versus U.S dollar). Non-linear CobbDouglas function was used to measure the long run elasticity. The results of this study suggest that the Canadian stock market return, exchange rate and COP have a trend over a period of time. They found a higher level of significance in the regression coefficients. The analysis shows that exchange rates and COP, both are significant on stock market that shows these two variables have influence on stock market. Such studies and their results have capabilities to draw the attention of investors towards the Canadian stock market.

Nusair and Al-Khasawneh (2017) studied the impact of oil price shocks on the returns 
of stock markets of the countries involved in the Gulf Cooperation Council. The methodology adopted in this study for analysis is the quantile regression analysis. Further, they used asymmetry and structural breaks by describing the difference between negative and positive changes in oil prices. The quantile regression, unlike OLS analysis, enables the coefficient estimates to change in the overall dependent variable distribution that gives a detailed view of the association between the dependent variable and the explanatory variables. Results obtained from this study showed that there is no consistency in coefficient estimates in the overall stock returns' distribution. Additionally, it showed that there are irregular effects of oil price shocks on the stock returns. It also showed that the stock market conditions have effects on the overall impact of oil price shocks on the returns of stock market.

Nusair and Olson (2019) studied the impact of oil price shocks on the exchange rate in Asia. They used the quantile regression analysis and provided room for the structural breaks and irregularities. The results showed that the negative and positive shocks in oil prices have irregular impacts on the returns of exchange rate that fluctuate in size, importance and sign in the overall exchange rates returns distribution. The market conditions (including bullish and bearish currency markets) also affect the oil price shocks. In domestic currencies during the bullish markets, (the movement of currency at lower quantiles in U.S. dollar rate of exchange), increase in oil prices affects further increase in the currencies of Thailand, Korea, Indonesia and the Philippines. In domestic currencies during the bearish markets (the movement of exchange rate at higher quantiles in U.S. dollar rate of exchange), falling (rising) prices of oil affects further depreciation of currency in Malaysia (Indonesia).

Zhu et al. (2016) investigated the relationship between the changes in real price of crude oil and the stock market returns in Chinese real industry on the basis of monthly data gathered for the period from 1994/03 to 2014/06. The issue was discussed in this paper through the quantile regression approach since it gives a detailed explanation of the degree and structure of this relationship. The results of this analysis showed that there is a heterogeneous reaction of market returns towards crude oil in the conditional distribution of industrial stock returns. Furthermore, this study reveals that this is positive dependence and this happens only in recession time or in the bearish markets that have lower expected returns. The low quantile dependence is there not only in one market but this trend is common all over the industries. Further, this dependence has changes also due to the structural breaks. The authors identified that the global crude oil markets and the Chinese industry stock are opposite to each other but only in rare cases.

\section{Methodology}

\section{Sample Data}

The study used a balanced panel data with annual frequency from 1995 to 2017. The sample period was selected on the basis of data availability. Moreover, the study has purposefully selected top oil importing countries which include China, France, Germany, 
Italy, Japan, South Korea, Spain and United States for assessing the effects of oil price and exchange rate on their stock market performance. The selection of aforementioned eight countries among top oil-importing countries was based on the availability of data; whereby, the data were extracted from World Development Indicator (WDI), Global Financial Development Indicator (GFDI), and West Texas Intermediate (WTI).

\section{Regression Model}

Based on past studies, the following regression model is used to examine the proposed relationship between oil price and stock market performance.

$$
(S M R)_{i t}=\alpha+\beta_{1}(O P)_{i t}+\beta_{2}(E R)_{i t}+\beta_{3}(G D P)_{i t}+\beta_{4}(I N F)_{i t}+\epsilon_{i t}
$$

Where; SMR denoted as stock market performance measured by stock market return in annual percentage, OP denoted as oil prices measured in US dollar per barrel from WTI, ER denoted as exchange rate measured in index (2010) from World Bank, GDP denoted as economic growth measured in terms of annual real GDP in percentage, and INF denoted as inflation measured in consumer price index annual percentage. Moreover, $\epsilon$ denoted as error term or residual for ith country at time $\mathrm{t}$ while $\alpha$ is the constant term and $\beta$ is the standardized coefficient value.

\section{Estimation Procedure}

This study employed a static panel data approach to run the analysis. We first used a pooled ordinary least square (POLS) and random effect model (REM). Ali (2016) argued that POLS estimations follows ordinary least square (OLS) assumptions and applied on panel data sets. Moreover, POLS violates the basic assumptions of orthogonality and ignores the individual effect. Similarly, REM counters this problem and employed an individual specific intercept in the panel regression. However, the intercept should allow exogeneity and randomness in the model. After this, we applied Hausman test to check the model suitability whether fixed effect model (FEM) or random effect model (REM) is appropriate. Earlier studies highlighted the fact that the problem of endogeneity should not be ignored in panel data set. In this condition, the FEM provide better and consistent estimates. This study also used diagnostic tests to confirm the reliability of the estimators. This is possible using multicollinearity, heteroscedasticity and serial correlation tests.

\section{Empirical Findings}

To analyze the strength of the relationship between independent variables, the study used person correlation matrix. The correlation test suggests whether or not the effect of one independent variable over the other produce any multicollinearity problem (Ali, 2016). In other words, if the correlation between the independent variables is greater than 0.90 , then the chances of multicollinearity problem arise (Ali \& Puah, 2019; Masood \& Ashraf, 
2012; Arif \& Nauman Anees, 2012; Ali, 2016). Therefore, the problem of multicollinearity is tested and found that the correlation among the variables is appropriate while the multicollinearity issue is not a problem for this study. Hence, the results of the correlation matrix are reported in Table 1.

Table 1

\begin{tabular}{lcccc}
\multicolumn{6}{l}{ Correlation matrix } \\
\hline & GDP & INF & OP & ER \\
\hline GDP & 1.000 & & & \\
INF & 0.297 & 1.000 & & \\
OP & -0.173 & -0.029 & 1.000 & \\
ER & 0.063 & -0.024 & -0.061 & 1.000 \\
\hline
\end{tabular}

\section{Regression Analysis}

In the first step, the panel regression model is analyzed using the POLS model and RE models. In order to attain robust and consistent results, we performed two tests POLS and $\mathrm{RE}$ to compare with Breusch-Pagan Lagrange multiplier test statistics. The null hypothesis of Breusch-Pagan Lagrange multiplier test states that the intercept term and slope term is constant. This shows that if the p-value for Breusch-Pagan Lagrange multiplier test is insignificant, the POLS model is appropriate for estimations while RE model is preferred whereas if the p-value for Breusch-Pagan Lagrange multiplier test is significant, hence the null hypothesis is rejected. In this study, we found Breusch-Pagan Lagrange multiplier test value significant at 1 percent significance level. This result confirms the rejection of the null hypothesis, state that the intercept and slope terms are constant. This implies that we can accept RE model rather POLS model. Furthermore, we employed Hausman test to further compare whether FE or RE model is better for estimations. The rejection of null hypothesis indicates that FE model is a suitable model then RE model. Hence, we use FE model to interpret the final results. Additionally, our diagnostic test results suggest that our results are free from the problems related to multicollinearity, heteroscedasticity and serial correlation. Table 2 depicts the overall results of regression analysis.

Table 2

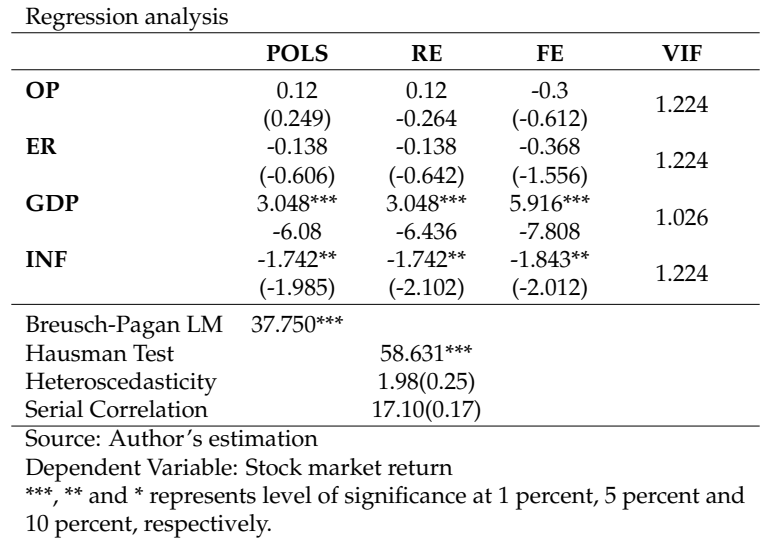


In earlier studies, there exists a consensus among the researchers to study the direction of causality between study variables (Raza, Jawaid, \& Shafqat, 2013; Ali, 2016; Ali \& Puah, 2018). We used Jones (1989) ad hoc lag length selection to run the Granger causality test. Raza et al. (2013) argued that this approach is superior among other statistical methods to attain optimal lag length selection. Therefore, our analysis proceeds with Granger causality test to analyze the direction of causality among the variables. The results indicate that there exist a bi-directional causality running from SMR to GDP and GDP to SMR. Similarly, SMR to INF and INF to SMR also shows a bi-directional causality. On the other side, we found unidirectional causality running from SMR to OP while no causality found between SMR and ER. Table 3 is reported with the results of Granger causality test.

Table 3

Granger causality

\begin{tabular}{lccc}
\hline Null Hypothesis & F-Statistic & Prob. & Remarks \\
\hline SMR does not Granger Cause GDP & 7.888 & $0.001^{* * *}$ & \multirow{2}{*}{ Bidirectional } \\
GDPG does not Granger Cause SMR & 4.296 & $0.015^{* *}$ & \\
SMR does not Granger Cause INF & 9.97 & $0.000^{* *}$ & Bidirectional \\
INF does not Granger Cause SMR & 2.662 & $0.073^{*}$ & \\
SMR does not Granger Cause OP & 9.622 & $0.000^{* * *}$ & Unidirectional \\
OP does not Granger Cause SMR & 0.74 & 0.479 & \\
SMR does not Granger Cause ER & 0.833 & 0.437 & None \\
ER does not Granger Cause SMR & 1.721 & 0.182 & \\
Source: Author's estimation & \\
***,** and * represents level of significance at 1 percent, 5 percent and 10 percent, \\
respectively.
\end{tabular}

\section{Conclusion and Discussions}

This aim of this study is to examine the impact of oil prices on stock market performance, particularly in top oil importing countries. We used a balanced panel data over a sample period from 1995 to 2017. This study also employed exchange rate, GDP and inflation rate as controlling variables. The results of the study suggest that the impact of oil prices is insignificant on stock market return. More precisely, fluctuations or change in oil prices doesn't lead towards the fluctuation in the stock market return. Maghyereh and Al-Kandari (2007) revealed that the shocks in oil prices do not reveal any empirical evidence on stock performance. Even though the relationship is insignificant but the FEM shows that the direction of the relationship is negative. It is opposite to the study of Adetunji Babatunde et al. (2013) who analyzed the influence of oil prices on stock market and proposed that oil prices are positively connected with stock market return either the country is oil importer or exporter. Furthermore, Raza, Shahbaz, Amir-ud Din, Sbia, and Shah (2018); Boubaker and Raza (2017) noted the influence of oil prices on stock performance. Hence, our findings show partial consistent results with Kumar and Maheswaran (2013) study, which shows the impact of oil prices on stock market.

Secondly, the outcome of exchange rate is contradictory with the findings of Alzyoud et al. (2018); Liao et al. (2018), while results are similar with the studies of Le and Chang (2012). These studies show that exchange rate is insignificantly related to the stock market return. In the same vein, Aloui et al. (2013) propose that stock prices are weakly correlated 
with the exchange rates. Similarly, You et al. (2017) showed that exchange rate is insignificantly related to the stock market return. The empirical evidence provided by Hu et al. (2018); Le and Chang (2012) suggested that the inexperienced stock markets get affected by the rumors which tend to confuse the investors. In this manner, the actual scenario doesn't influence the performance of stock market. Hence, fluctuation in exchange rates does not directly impact the stock market return (Diaz \& de Gracia, 2017; Ghosh, 2009).

Further, results of GDP growth provided the evidence that it is the crucial indicator of stock market return. This signifies that GDP growth has a significant and positive impact on stock market performance (Ghosh, 2009). There are numerous studies that supported the view that stock market is basically the reflection of the economic growth (Hamdi \& Sbia, 2013; Zhang \& Jiang, 2017). It is also argued that stock market performance usually interpret the improving conditions of the economy in terms of productivity and employment (Silvapulle, Smyth, Zhang, \& Fenech, 2017); therefore, due to increased productivity and low unemployment rate, poverty declines, welfare of the individual takes place and overall prosperity of the economy shows improvement (Alzyoud et al., 2018).

Numerous studies have shown that there has been and negative relationship between inflation and stock market performance (Adetunji Babatunde et al., 2013). In this regards due to high inflation, the savings patterns decline which negatively influences on stock market (Maghyereh \& Al-Kandari, 2007). Moreover, it has also been posited an empirical study that due to inflation the economic productivity reduces based on the rationale that higher prices of the commodity lead to high cost of production and therefore economic production declines (Mohanty et al., 2018); thus, the results of the present study found consistent with numerous past evidence (Hu et al., 2018; Ji et al., 2018).

\section{Policy Implications}

This findings of this study provide important but useful policy guidelines. The influence of oil prices on stock market is insignificant but exhibiting a positive connection with stock market returns. As a matter of fact, governments normally try to reduce the shocks of certain factors through the provision of subsidies in order to sustain or stabilize the economy. In this case, the impact of oil prices might be nullified due to government expenditures. Moreover, it is possible that a change in oil prices may only disturb the energy sector. Whereas other industries would be functioning properly, due to the rescue plan of government in the form of subsidies that minimizes the risk for individual investors and household consumers. Secondly, the findings concern with the exchange rate is similar to the oil prices as it is insignificantly impacting on stock market return. For this purpose, it is recommended to sustain the market environment in order to attract more capital in form of domestic or foreign investment. Moreover, it should be required to develop an appropriate policy of exchange rate that improves the stability of stock market returns. By analyzing and maintaining better policies of exchange rate, it should be possible to predict the status of stock market return through exchange rate fluctuation. Thirdly, it is suggested to work on activities that help to enhance the economic growth as GDP growth tends to improve the stock market return in oil importing nations. For this purpose, government and policymakers need to focus on improved monetary policy in 
order to increase the supply of money in the market. This will result in more consumption that will consequently improve the level of GDP.

\section{Future Directions}

This study used a balanced panel data of top oil importing countries. Hence, it is advised to focus on the time series data in order to develop an in-depth understanding about the consequences of oil prices on stock market. It is recommended to replicate this is study in the perspective of other developing countries to get more useful insights. Lastly, researchers can include other macroeconomic variables as controlling factors to assess the relationship between oil price and stock market performance. 


\section{References}

Adetunji Babatunde, M., Adenikinju, O., \& Adenikinju, A. F. (2013). Oil price shocks and stock market behaviour in Nigeria. Journal of Economic Studies, 40(2), 180-202.

Algahtani, G. J. (2016). The effect of oil price shocks on economic activity in Saudi Arabia: Econometric approach. International Journal of Business and Management, 11(8), 124 133.

Al-hajj, E., Al-Mulali, U., \& Solarin, S. A. (2017). The influence of oil price shocks on stock market returns: Fresh evidence from Malaysia. International Journal of Energy Economics and Policy, 7(5), 235-244.

Ali, M. (2016). Bank profitability and its determinants in Pakistan: A panel data analysis after financial crisis. Journal of Finance E Economic Research, 1(1), 3-16.

Ali, M., \& Puah, C.-H. (2018). Does bank size and funding risk effect banks' stability? A lesson from Pakistan. Global Business Review, 19(5), 1166-1186.

Ali, M., \& Puah, C. H. (2019). The internal determinants of bank profitability and stability: An insight from banking sector of Pakistan. Management Research Review, 42(1), 4967.

Aloui, R., Hammoudeh, S., \& Nguyen, D. K. (2013). A time-varying copula approach to oil and stock market dependence: The case of transition economies. Energy Economics, 39, 208-221.

Alrub, A. A., Rjoub, H., Aga, M., Bein, M., et al. (2018). Exploring the stock price correspondence to oil price shocks in the Gulf cooperation council countries: Evidence from linear (symmetric) model. International Journal of Economics and Financial Issues, $8(1), 250-257$.

Alzyoud, H., Wang, E. Z., \& Basso, M. G. (2018). Dynamics of Canadian oil price and its impact on exchange rate and stock market. International Journal of Energy Economics and Policy, 8(3), 107-114.

Arfaoui, M., \& Ben Rejeb, A. (2017). Oil, gold, US dollar and stock market interdependencies: A global analytical insight. European Journal of Management and Business Economics, 26(3), 278-293.

Arif, A., \& Nauman Anees, A. (2012). Liquidity risk and performance of banking system. Journal of Financial Regulation and Compliance, 20(2), 182-195.

Basher, S. A., Haug, A. A., \& Sadorsky, P. (2017). The impact of oil-market shocks on stock returns in major oil-exporting countries: A markov switching approach. Available at SSRN 3046052.

Boubaker, H., \& Raza, S. A. (2017). A wavelet analysis of mean and volatility spillovers between oil and BRICS stock markets. Energy Economics, 64, 105-117.

Degiannakis, S., Filis, G., \& Panagiotakopoulou, S. (2018). Oil price shocks and uncertainty: How stable is their relationship over time? Economic Modelling, 72, 42-53.

Diaz, E. M., \& de Gracia, F. P. (2017). Oil price shocks and stock returns of oil and gas corporations. Finance Research Letters, 20, 75-80.

Ewing, B. T., Kang, W., \& Ratti, R. A. (2018). The dynamic effects of oil supply shocks on the US stock market returns of upstream oil and gas companies. Energy Economics, $72,505-516$. 
Fowowe, B. (2017). Return and volatility spillovers between oil and stock markets in South Africa and Nigeria. African Journal of Economic and Management Studies, 8(4), 484-497.

Ghorbel, A., Abbes Boujelbene, M., \& Boujelbene, Y. (2014). Behavioral explanation of contagion between oil and stock markets. International Journal of Energy Sector Management, 8(1), 121-144.

Ghosh, S. (2009). Import demand of crude oil and economic growth: Evidence from India. Energy Policy, 37(2), 699-702.

Hamdi, H., \& Sbia, R. (2013). Dynamic relationships between oil revenues, government spending and economic growth in an oil-dependent economy. Economic Modelling, 35, 118-125.

Hu, C., Liu, X., Pan, B., Chen, B., \& Xia, X. (2018). Asymmetric impact of oil price shock on stock market in China: A combination analysis based on SVAR model and NARDL model. Emerging Markets Finance and Trade, 54(8), 1693-1705.

Ji, Q., Liu, B.-Y., Zhao, W.-L., \& Fan, Y. (2018). Modelling dynamic dependence and risk spillover between all oil price shocks and stock market returns in the BRICS. International Review of Financial Analysis.

Jones, J. D. (1989). A comparison of lag-length selection techniques in tests of Granger causality between money growth and inflation: Evidence for the US, 1959-86. Applied Economics, 21(6), 809-822.

Kang, W., Ratti, R. A., \& Vespignani, J. L. (2017). Oil price shocks and policy uncertainty: New evidence on the effects of US and non-US oil production. Energy Economics, 66, 536-546.

Kumar, D., \& Maheswaran, S. (2013). Return, volatility and risk spillover from oil prices and the US dollar exchange rate to the Indian industrial sectors. Margin: The Journal of Applied Economic Research, 7(1), 61-91.

Le, T.-H., \& Chang, Y. (2012). Oil price shocks and gold returns. International Economics, 131, 71-103.

Liao, J., Shi, Y., \& Xu, X. (2018). Why is the correlation between crude oil prices and the US dollar exchange rate time-varying? Explanations based on the role of key mediators. International Journal of Financial Studies, 6(3), 61.

Maghyereh, A., \& Al-Kandari, A. (2007). Oil prices and stock markets in GCC countries: New evidence from nonlinear cointegration analysis. Managerial Finance, 33(7), 449460.

Marashdeh, H., \& Afandi, A. (2017). Oil price shocks and stock market returns in the three largest oil-producing countries. International Journal of Energy Economics and Policy, 7(5), 312-322.

Masood, O., \& Ashraf, M. (2012). Bank-specific and macroeconomic profitability determinants of Islamic banks: The case of different countries. Qualitative Research in Financial Markets, 4(2/3), 255-268.

Mohanty, S. K., Onochie, J., \& Alshehri, A. F. (2018). Asymmetric effects of oil shocks on stock market returns in Saudi Arabia: Evidence from industry level analysis. Review of Quantitative Finance and Accounting, 51(3), 595-619. 
Mollick, A., \& Nguyen, K. H. (2015). US oil company stock returns and currency fluctuations. Managerial Finance, 41(9), 974-994.

Naser, H., \& Rashio, A. (2018). Oil price shocks and stock market performance in the BRICs: Some evidence using FAVAR models. Economics Issues, 23(2), 85-108.

Nusair, S. A., \& Al-Khasawneh, J. A. (2017). Oil price shocks and stock market returns of the GCC countries: Empirical evidence from quantile regression analysis. Economic Change and Restructuring, 51(4), 339-372.

Nusair, S. A., \& Olson, D. (2019). The effects of oil price shocks on Asian exchange rates: Evidence from quantile regression analysis. Energy Economics, 78, 44-63.

Raza, S. A., Jawaid, S. T., \& Shafqat, J. (2013). Profitability of the banking sector of Pakistan: Panel evidence from bank-specific, industry-specific and macroeconomic determinants.

Raza, S. A., Shahbaz, M., Amir-ud Din, R., Sbia, R., \& Shah, N. (2018). Testing for wavelet based time-frequency relationship between oil prices and US economic activity. Energy, 154, 571-580.

Ready, R. C. (2017). Oil prices and the stock market. Review of Finance, 22(1), 155-176.

Sharma, A., Giri, S., Vardhan, H., Surange, S., Shetty, R., \& Shetty, V. (2018). Relationship between crude oil prices and stock market: Evidence from India. International Journal of Energy Economics and Policy, 8(4), 331-337.

Silvapulle, P., Smyth, R., Zhang, X., \& Fenech, J.-P. (2017). Nonparametric panel data model for crude oil and stock market prices in net oil importing countries. Energy Economics, 67, 255-267.

Wong, V. S., \& El Massah, S. (2018). Recent evidence on the oil price shocks on Gulf cooperation council stock markets. International Journal of the Economics of Business, 25(2), 297-312.

Yao, C. Z., Kuang, P. C., \& Lin, J. N. (2018). The optimal thermal causal path analysis on the relationship between international crude oil price and stock market. Kybernetes, 47(6), 1242-1261.

You, W., Guo, Y., Zhu, H., \& Tang, Y. (2017). Oil price shocks, economic policy uncertainty and industry stock returns in China: Asymmetric effects with quantile regression. Energy Economics, 68, 1-18.

Zhang, Y., \& Jiang, Y. (2017). Robust optimization on sustainable biodiesel supply chain produced from waste cooking oil under price uncertainty. Waste Management, 60, 329-339.

Zhu, H., Guo, Y., You, W., \& Xu, Y. (2016). The heterogeneity dependence between crude oil price changes and industry stock market returns in China: Evidence from a quantile regression approach. Energy Economics, 55, 30-41. 